\title{
Electrochemical Glucose Quantification as a Strategy for Ethanolic Fermentation Monitoring
}

\author{
Isabel Acevedo-Restrepo ${ }^{1}$, Lucas Blandón-Naranjo ${ }^{1}$, Jorge Hoyos-Arbeláez ${ }^{1}{ }^{\mathbb{D}}$, \\ Flavio Della Pelle ${ }^{2}$ (1) and Mario V. Vázquez ${ }^{1, *}$ \\ 1 Grupo Interdisciplinario de Estudios Moleculares-GIEM, Instituto de Química, Universidad de Antioquia, \\ Calle 67 No. 53-108, Medellín A.A 1226, Colombia; disabel.acevedo@udea.edu.co (I.A.-R.); \\ lucas.blandon@udea.edu.co (L.B.-N.); jandres.hoyos@udea.edu.co (J.H.-A.) \\ 2 Faculty of Biosciences and Technologies for Food, Agriculture and Environment, University of Teramo, \\ 64023 Teramo, Italy; fdellapelle@unite.it \\ * Correspondence: mario.vazquez@udea.edu.co; Tel.: +57-4-2195652
}

Received: 23 January 2019; Accepted: 12 March 2019; Published: 15 March 2019

\begin{abstract}
The possibility of using an electrochemical biosensor, using screen-printed electrodes modified with a carbonaceous material and a commercial kit for the determination of glucose, to monitor an ethanolic fermentation was analyzed. The determination is based on the electrochemical oxidation reaction of NADH that occurs at a potential where the components of the kit do not generate a current signal, even in the presence of the fermentation medium. The electrochemical system was used to analyze the variation of glucose concentration during a laboratory-scale fermentation. The results were contrasted with the variation of standard characterization parameters such as $\mathrm{pH}$, total soluble solids (TSS), the viability of the yeast, and concentration of ethanol produced. Of these values, the total soluble solids should be related to the concentration of glucose obtained by the electrochemical sensor, however, this last measure is more specific for sugar since the TSS refers to all soluble solids. The obtained results allow us to verify the usefulness of the electrochemical method for real-time monitoring of a fermentation.
\end{abstract}

Keywords: fermentation; NADH; glucose; cyclic voltammetry; chronoamperometry; electrochemical sensor; biosensor

\section{Introduction}

Fermentation is a catabolic process of incomplete oxidation, which does not require oxygen and whose final products are organic compounds, which, depending on factors such as the substrate, culture medium, and type of microorganism, can range from low molecular weight organic acids (acetic acid, lactic acid, butyric acid, etc.) to low molecular weight alcohols (propanol, methanol or ethanol) [1,2]. Many efforts have been devoted to the characterization and control of this type of bioprocesses, due to its economic importance for the production of vinegar, wines, and substances of interest such as lactic acid, among many others [3,4].

The ethanolic fermentation processes involve the transformation of sugars (mainly glucose, fructose, and sucrose) into ethanol and carbon dioxide. Although several types of microorganisms can drive fermentation processes, industrially, the yeast Saccharomyces cerevisiae is the most used, because of its tolerance to relatively high concentrations of ethanol. The maximum concentration of ethanol produced in a classical fermentative process is around $12-14 \%(v / v)$; over these concentrations, the ethanol acts as a "yeast inhibitor" [2].

During fermentation, enzyme-mediated oxidation-reduction processes occur simultaneously, which enhances the use of electrochemical analysis techniques as a powerful tool for the characterization of 
fermentations and in particular of ethanolic fermentations [3-5]. In particular, amperometric detection has been used as a tool for the quantification of molecules such as ethanol, glucose, and fructose, which are part of the ethanolic fermentation process. Usually, amperometric detection implies the use of enzymes as recognition elements thanks to the high selectivity that these macromolecules confer, and in addition to the possibility of monitoring molecules such as glucose or fructose, which are non-electroactive species [3-6].

From the electrochemical point of view, there are two stages of the reaction in which there is a net charge transfer between molecules. These stages involve the presence of $\mathrm{NAD}^{+}$an NADH (Nicotinamide adenine dinucleotide) either during the process of oxidation of glyceraldehyde-3phosphate to 1,3-diphosphoglycerate (during glycolysis) or in the reduction of acetaldehyde to ethanol (in the final stage of fermentation) $[2,7,8]$.

The stages in which the NADH/NAD+ redox couple participates (glycolysis and fermentation) are the only ones that include an electron transfer process [8,9]. The net oxidation-reduction reaction for this redox couple is schematized as showed in Equation (1).

$$
N A D^{+}+H^{+}+2 e^{-} \leftrightarrow N A D H
$$

Due to the biological importance of the NADH/NAD+ redox couple, which participates as a cofactor in more than 300 enzymatic reactions, several studies have been conducted to understand its electrochemical behavior that is related to its biological activity [10-12].

The oxidation of NADH occurs at relatively high overpotentials and involves the transfer of two electrons, one proton, and the formation of the $\mathrm{NAD}^{+}$species. $\mathrm{NAD}^{+}$reduction also occurs at high overpotentials and generates the NADH molecule again $[8,9,13]$. The biological importance of this redox system means that, in addition to the study of electrochemical behavior, it is also of great interest for its application to the design of electrochemical biosensors that include the NADH molecule coupled to enzymatic systems, which allows the possibility of indirectly measuring many substrates of biological interest $[8,14,15]$. Several studies have shown that the use of carbonaceous materials, as electrodes surfaces, facilitates the oxidation of NADH [16-19]. Different allotropes of carbon have been tested, such as graphite, vitreous carbon, and pyrolytic graphite, among others, obtaining good responses related to the overpotential decrease and the increase in the response current for the oxidation of NADH [8]. Nanomaterials have received great attention in recent years in different fields, in particular in analytical chemistry, due to their enormous potential, thanks to their excellent unique optical, electrical, magnetic, catalytic, biological, or mechanical properties [20,21]. Indeed, nanostructured sensors allow improving the sensitivity and selectivity providing larger surface area and faster electron transfers in comparison with their bulk counterparts [21,22].

For these reasons, in the last years, several works have been reported on the carbon nanomaterials as electrode modifier, showing remarkable electrocatalytic properties towards several species of analytical interest [22-25], allowing the realization of a new electrochemical device [26-28]. Among these materials, carbonaceous nanomaterials have been largely successfully exploited to realize NADH sensors, showing improved properties in term of selectivity, sensitivity, and catalytic activity $[15,17,19]$.

The catalytic property of the oxidized-multiwalled carbon nanotubes (O-MWCNT) via controlled microwave towards the NADH oxidation, has been recently demonstrated. In the proof of concept of sensor usability, the MWCNT-controlled oxidation has been optimized, obtaining superficial oxygenated groups able to facilitate the NADH's deprotonation during the oxidative process [19]. The achieved sensors designed with this material showed good reproducibility and repeatability. The possibility of quantifying glucose in white wine using a commercial enzymatic kit coupled to the designed sensor has been reported [29].

The aim of this work was to demonstrate the utility of screen-printed electrodes modified with O-MWCNTs for monitoring glucose in a fast and easy way in an ethanolic fermentation real process. 


\section{Materials and Methods}

\subsection{Materials and Reagents}

NADH, with a purity of $99.9 \%$, was acquired in Panreac ${ }^{\circledR}$ (Barcelona, Spain). The phosphate buffer (PBS) was prepared at a concentration of $0.01 \mathrm{~mol} \cdot \mathrm{L}^{-1}$ at $\mathrm{pH} 7.0$ from potassium monobasic phosphate $\left(\mathrm{KH}_{2} \mathrm{PO}_{4}\right.$, Sigma, St. Louis, $\mathrm{MO}$, USA) and potassium dibasic phosphate $\left(\mathrm{K}_{2} \mathrm{HPO}_{4}, \mathrm{Sigma}\right)$; potassium chloride, $\left(\mathrm{KCl}\right.$, Merck, Darmstadt, Germany) $0.1 \mathrm{~mol} \cdot \mathrm{L}^{-1}$ was used as supporting electrolyte. Potassium hexacyanoferrate (II) trihydrate solution $\mathrm{K}_{3}\left[\mathrm{Fe}(\mathrm{CN})_{6}\right] \cdot 3 \mathrm{H}_{2} \mathrm{O}$ (Sigma, St. Louis, Missouri, USA) was prepared at a concentration of $1 \times 10^{-3} \mathrm{~mol} \cdot \mathrm{L}^{-1}$ in $0.1 \mathrm{~mol} \cdot \mathrm{L}^{-1} \mathrm{KCl}$. Commercial sucrose ( $98 \%$ purity), peptone (Merck, Darmstadt, Germany), and Saccharomyces cerevisiae were employed to carry out the fermentation. Other reagents used were methylene blue (Sigma, St. Louis, MO, USA), sodium chloride (Merck, Darmstadt, Germany), and ethanol (Merck, Darmstadt, Germany).

Screen printed electrodes (SPE) manufactured by DropSens ${ }^{\circledR}$ (DS) (Llanera, Asturias, Spain) with a three-electrode configuration (geometric areas of $7.06 \mathrm{~mm}^{2}$ ) were employed. Commercially available, multi-walled carbon nanotubes (MWCNTs, Nano-Lab, Waltham, Massachusetts, USA) were oxidized in a microwave-assisted acid medium for 15 min according to Blandón-Naranjo et al. [15]. The oxidized nanotubes were denominated CNT15. All electrochemical measurements were performed with a prior nitrogen purge.

The electrochemical and spectrophotometric measurement of glucose was performed using the commercial enzyme kit for glucose GAHK-20 (Sigma, St. Louis, MO, USA), composed of NAD ${ }^{+}$ $1 \mathrm{mmol} \cdot \mathrm{L}^{-1}$, ATP $1.0 \mathrm{mmol} \cdot \mathrm{L}^{-1}$, hexokinase $1.0 \mathrm{U} \cdot \mathrm{mL}^{-1}$, and glucose-6-phosphate dehydrogenase $1 \mathrm{U} \cdot \mathrm{mL}^{-1}$. All reagents were dissolved in a buffer prepared with sodium benzoate and potassium sorbate at $\mathrm{pH} 7.8$.

\subsection{Screen Printed Electrode Modification and Characterization}

Prior to the O-MWCNT modification of the SPEs, they were washed with Milli Q water and cycled 10 times in PBS $\left(0.01 \mathrm{~mol} \cdot \mathrm{L}^{-1} ; \mathrm{KCl} 0.1 \mathrm{~mol} \mathrm{~L}-1\right.$ at $\left.\mathrm{pH} 7.0\right)$ using a potential window form -0.2 to $1.0 \mathrm{~V}$ at a scan rate of $0.1 \mathrm{~V} \cdot \mathrm{s}^{-1}$, to ensure a constant capacitive current. For the SPEs modification, an aqueous dispersion of O-MWCNT $\left(1 \mathrm{mg} \cdot \mathrm{mL}^{-1}\right)$ was prepared with $2 \mathrm{~h}$ of stirring (DLAB, MS-H280-Pro) followed by $2 \mathrm{~h}$ of sonication. Ten microliters of the prepared dispersion (two additions of $5 \mu \mathrm{L}$ ) were drop cast upon the SPE's surface and dried at room temperature. After immobilization, the modified electrode was cycled between $-0.2 \mathrm{~V}$ and $1.0 \mathrm{~V}$ in PBS $\left(0.01 \mathrm{~mol} \cdot \mathrm{L}^{-1} ; \mathrm{KCl} 0.1 \mathrm{~mol} \cdot \mathrm{L}^{-1}\right.$ at $\left.\mathrm{pH} 7.0\right)$ until a constant capacitive current was obtained. The prepared electrode was named SPE/O-MWCNT. In addition, electrodes modified with non-oxidized MWCNT (SPE/MWCNT) were prepared in order to compare the electrochemical behavior of both systems.

Morphological and surface characterization of SPE, SPE/MWCNT, and SPE/O-MWCNT was carried out by Scanning Electron Microscopy (SEM) in a JEOL-JSM 6490LV (JEOL Ltd. Akishima, Tokyo, Japan) microscope using augments of $\times 10,000$ and $\times 40,000$.

The electrodes were characterized electrochemically by calculating the electroactive area and the heterogeneous transfer constant. The electroactive area was calculated by cyclic voltammetry at different scan rates $\left(5,10,20,40,80,100\right.$, and $\left.200 \mathrm{mV} \cdot \mathrm{s}^{-1}\right)$, calculating the slope obtained by plotting the square root of the scanning rate $\left(v^{1 / 2}\right)$ vs. the anodic and cathodic peak current value $\left(\mathrm{i}_{\mathrm{p}}\right)$, using a solution of Potassium hexacyanoferrate (II) $1 \mathrm{mmol} \cdot \mathrm{L}^{-1}$ in $0.1 \mathrm{KCl} \mathrm{mol} \cdot \mathrm{L}^{-1}$ To determine the electroactive area, the Randles-Sevcik equation was used [30]. The heterogeneous transfer constant $\left(\mathrm{k}^{0}\right)$ was calculated using the difference of the anodic and cathodic oxidation potentials obtained in the cyclic voltammetry experiments used to calculate the electroactive area, employing the method proposed by Nicholson [31], and considering $\alpha=0.5$ (taking into account that the ratio between the anodic and cathodic peak currents $\left(i_{p, a} / i_{p, c}\right)$ is close to 1$)$. For each electrode, a voltammetric measurement (potential window $0.1-0.6 \mathrm{~V}$, scan rate $10 \mathrm{mV} \cdot \mathrm{s}^{-1}$ ) of $\mathrm{NADH} 1 \mathrm{mmol} \cdot \mathrm{L}^{-1}$ was also carried out to verify the oxidation potential and the current response. 


\subsection{Ethanolic Fermentation}

The ethanolic fermentation was carried out using a destructive sampling methodology. Eight parallel experiments were prepared with the objective of taking each one as a specific point of measurement in a determined time. For each experiment, a culture medium composed of sucrose $25 \%$ $(m / v)$ and peptone $1 \%(m / v)$ as sources of carbohydrates and nitrogen, respectively, was used. The medium was sterilized and inoculated with $10 \mathrm{~g} \cdot \mathrm{L}^{-1}$ of commercial Saccharomyces cerevisiae that was "activated" at $37^{\circ} \mathrm{C}$ for $10 \mathrm{~min}$. The selected times to carry out the fermentation monitoring were: $0,3,5,7,24,26$, and $30 \mathrm{~h}$. For each time, total soluble solids (TSS), $\mathrm{pH}$, cell viability, and ethanol concentration were measured.

The $\mathrm{pH}$ of the samples was determined immediately after each fermentation time, using an Orion SA720 pH-meter (Waltham, Massachusetts, USA) directly on the "fermentation broth".

TSS were measured in a Brixco Instruments refractometer. The "fermentation broth" was previously centrifuged at $6000 \mathrm{rpm}$ for $5 \mathrm{~min}$ and then filtered through a cellulose filter paper (pore size $0.2 \mu \mathrm{m}$ ), the results have been expressed as ${ }^{\circ}$ Brix, which is understood as grams of soluble solids per $100 \mathrm{~g}$ of solution $\left(\mathrm{g} \cdot 100 \mathrm{~g}^{-1}\right)$.

For viability, $10 \mathrm{~mL}$ of "fermentation broth" was centrifuged at $6000 \mathrm{rpm}$ for $5 \mathrm{~min}$, the supernatant was discarded and $5 \mathrm{~mL}$ of PBS was used to resuspend the yeast "pellet". The obtained yeast solution was then centrifuged again at $6000 \mathrm{rpm}$ for $5 \mathrm{~min}$ and the supernatant was discarded again. The yeast was finally resuspended in $5 \mathrm{~mL}$ of $\mathrm{NaCl} 0.9 \mathrm{~mol} \cdot \mathrm{L}^{-1}$. The yeast viability was evaluated mixing $0.5 \mathrm{~mL}$ of the yeast suspension with $0.5 \mathrm{~mL}$ of methylene blue. The yeast viability evaluation was performed with an optical microscope. The results are expressed as percent of stained cells.

The percentage of ethanol was measured by Gas chromatography (Hewlett Packard, Santa Clara, California, USA), using the supernatant obtained in Step 1 in Section 2.1. The sample was previously filtered through a cellulose filter (pore size of $0.2 \mu \mathrm{m}$ ). The results have been expressed in $\mathrm{mL}$ of ethanol per $100 \mathrm{~mL}$ of solution. $\left(\mathrm{mL} \cdot 100 \mathrm{~mL}^{-1}\right)$.

\subsection{Electrochemical Measurements: Cyclic Voltammetry and Chronoamperometry}

All electrochemical measurements were carried out in a PGSTAT 101 potentiostat/galvanostat (Autolab, Utrecht, the Netherlands) with NOVA 1.11 software. All the potentials referred in the results correspond to the difference of the working electrode vs. the silver reference pseudo-electrode, which has a difference of $+100 \mathrm{mV}$ with respect to an $\mathrm{Ag}|\mathrm{AgCl}| \mathrm{KCl}$ reference electrode.

Cyclic voltammetry was used to verify the electrochemical behavior of all the components in the sample and check the possibility of interferences for the quantification step. All cyclic voltammetry experiments were carried out between +0.1 and $+0.9 \mathrm{~V}$ at a scan rate of $10 \mathrm{mV} \cdot \mathrm{s}^{-1}$.

The electrochemical quantification of glucose was carried by chronoamperometry, according to a procedure previously reported by Blandón-Naranjo [19], with some modifications to adapt the methodology to the commercial kit employed [32].

Chronoamperometry was used in a $2 \mathrm{~mL}$ cell with constant stirring. To account for the matrix effect, the calibration curves were constructed in the fermentation broth. To this aim, $10 \mu \mathrm{L}$ of doped yeast culture medium with different concentrations of glucose $\left(5,10,50,75,100,150\right.$, and $\left.200 \mathrm{mg} \cdot \mathrm{L}^{-1}\right)$ were added to $90 \mu \mathrm{L}$ of the commercial glucose-kit mixture. Then, it was incubated for $15 \mathrm{~min}$ at $30^{\circ} \mathrm{C}$ in accordance with the kit supplier guidance, mixing $100 \mu \mathrm{L}$ of the commercial glucose-kit mixture with $1.9 \mathrm{~mL}$ of phosphate buffer. A potential difference of $0.3 \mathrm{~V}$ was applied and the current was recorded at $1 \mathrm{~min}$ (time needed to reach the steady state) and the corresponding calibration curve was made.

To monitor the fermentation, samples were taken at different times. The samples were diluted 1:10 in PBS $\left(0.01 \mathrm{~mol} \cdot \mathrm{L}^{-1} ; \mathrm{KCl} 0.1 \mathrm{~mol} \cdot \mathrm{L}^{-1}\right.$ at $\left.\mathrm{pH} 7.0\right)$, and then $10 \mu \mathrm{L}$ of the diluted samples were mixed with $90 \mu \mathrm{L}$ of the commercial glucose kit. Then, the mixture was incubated for $15 \mathrm{~min}$ at $30^{\circ} \mathrm{C}$, and subsequently added to $1.9 \mathrm{~mL}$ of phosphate buffer and measured. 
All measurements were performed using SPE/O-MWCNT, and each point of the curve was carried out with a different electrode (even for monitoring the fermentation).

\section{Results and Discussions}

\subsection{Sensor Characterization}

To verify the morphology of the sensor surface, SEM micrographs were taken for the unmodified SPE, an SPE modified with MWCNT before surface oxidation and after the microwave oxidation. The images are shown in Figure 1. Figure 1A shows the unmodified electrode, in which a rugose surface can be seen which is common in this kind of electrodes. Figure 1B shows the surface of the electrode covered by non-oxidized MWCNT. It must be noted that, although carbon nanotubes were observed, the surface was not regular and agglomerates were formed. On the other hand, when O-MWCNT were deposited over the surface of SPE, well-dispersed clusters of nanotubes were observed and the uncoated areas decreased significantly. This is confirmed in Figure 1D with higher magnification. A well covered dispersed O-MWCNT was observed. The effect of the well-organized surface over the SPE for the NADH oxidation is discussed in a previous work [19], in which it is reported that the presence of oxygenated groups facilitates the dispersion of the material in water and, then, it improves the material dispersion when a drop is coated over the surface of SPE.
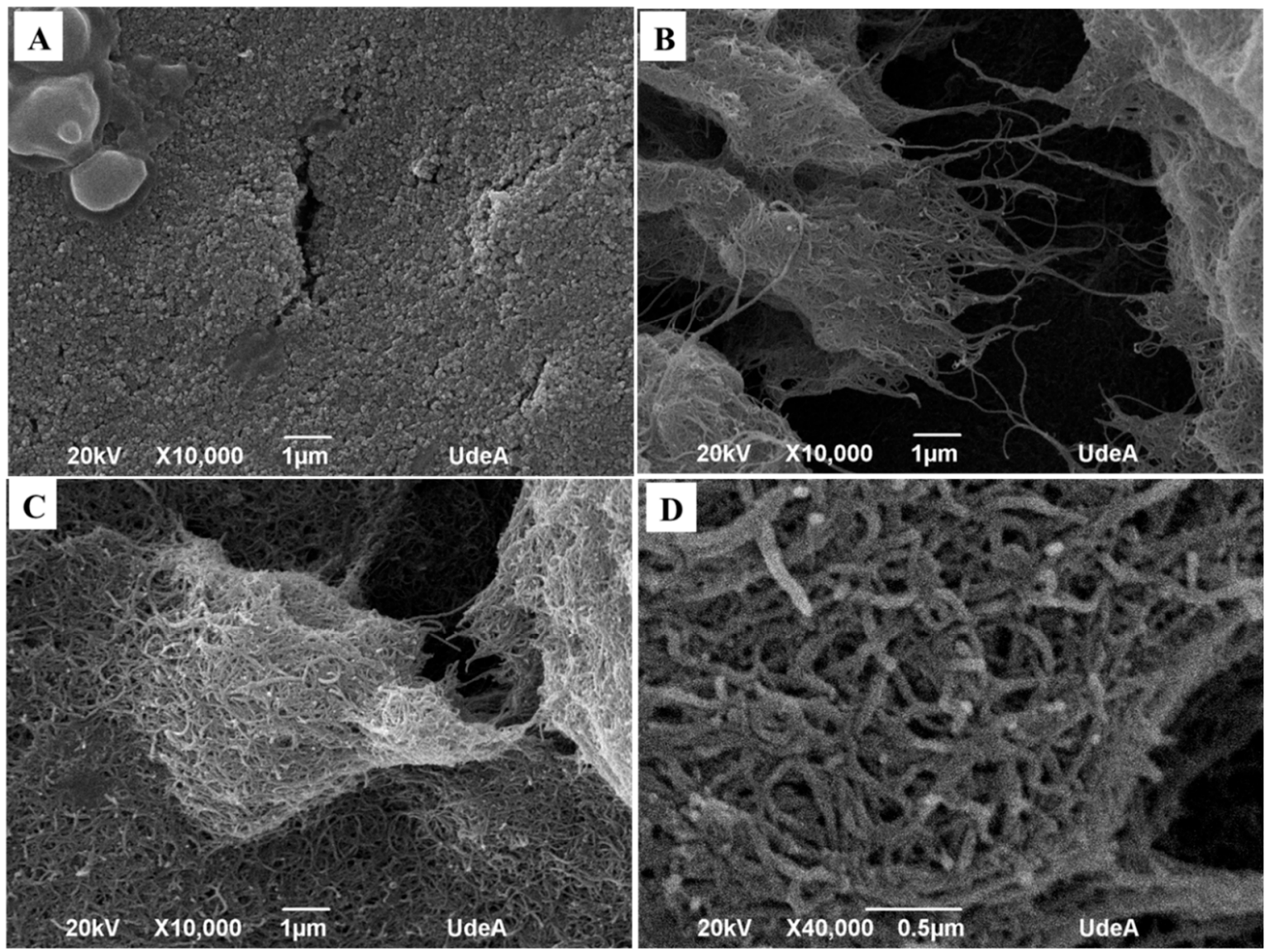

Figure 1. SEM micrographs of: an unmodified screen-printed electrode (A); a screen-printed electrode modified with non-oxidized MWCNT (B); and screen-printed electrode modified with O-MWCNT with an augment of: $\times 10,000(\mathbf{C})$; and $\times 40,000(\mathbf{D})$.

Figure 2 shows the voltammetric studies carried out in a Potassium hexacyanoferrate (II) solution as a redox reference system. In Figure $2 \mathrm{~A}$, the comparison of the three electrodes at the same scan rate is shown. It can be noted that, when the electrode was covered by carbon nanotubes (oxidized and 
non-oxidized), the current peak increased considerably due to the augment in the electroactive area improved by the carbon nanomaterial. In addition, the difference between the oxidation and reduction potential of peaks decreased, which was related to the augment in the heterogeneous constant transfer according to Nicholson proposal [31]. Based on the Randles-Sevcik equation, if the redox process were controlled by diffusion, a linear relationship between the oxidation and reduction currents, as well as the square root of scan rate, would be obtained. Figure $2 \mathrm{~B}$ shows the behavior of the relationship previously described. A significant augment in the slope of the graphs for SPE/MWCNT and SPE/O-MWCNT was observed, which was related with the augment in the electroactive area of the material, covered by the nanomaterial immobilized in the surface of SPE. On the other hand, there was no important difference between the slope of SPE/MWCNT and SPE/O-MWCNT as the oxygenated surface did not significantly improve the electroactive area. This agrees with previously obtained results $[15,19]$.

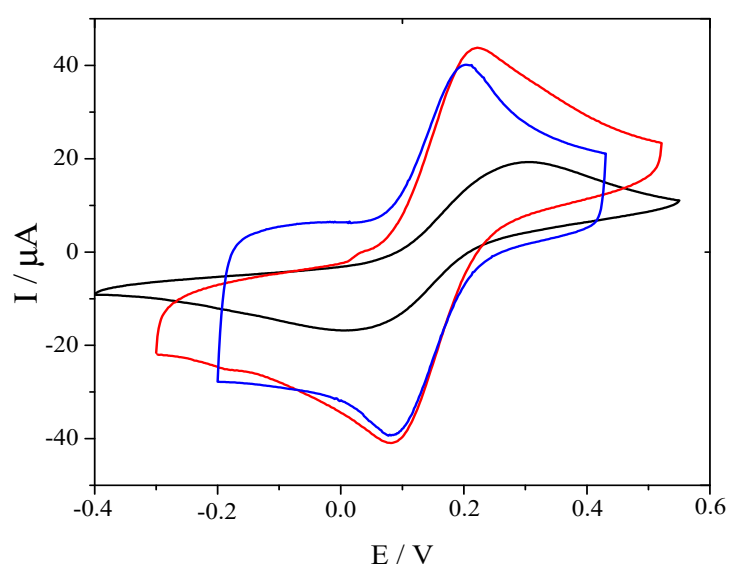

(A)

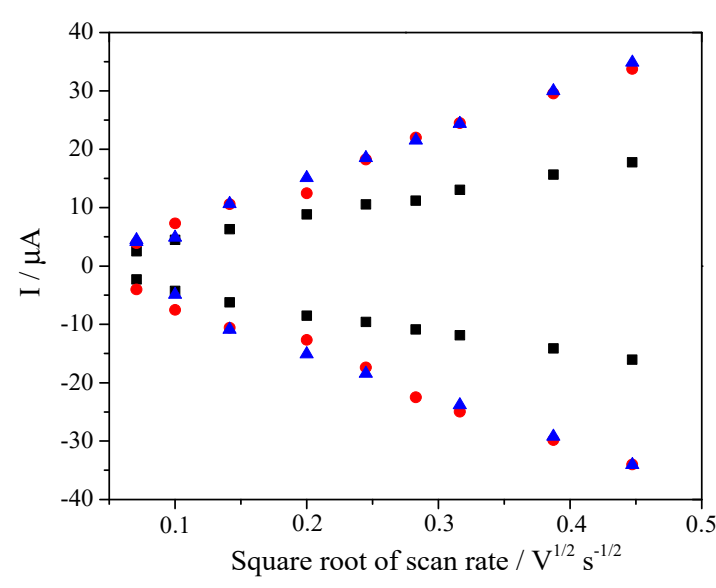

(B)

Figure 2. Voltammetric characterization of SPE (black), SPE/MWCNT (red), and SPE/O-MWCNT (blue): (A) comparison of cyclic voltammetries for the three electrodes at $100 \mathrm{mV} \mathrm{s}^{-1}$; and (B) anodic and cathodic current peaks for the three electrodes at different scan rates: 5, 10, 20, 40, 60, 80, 100, and $200 \mathrm{mV} \mathrm{s}^{-1}$. Probe solution: Potassium hexacyanoferrate (II) $1 \mathrm{mmol} \cdot \mathrm{L}^{-1}$ in $\mathrm{KCl} 0.1 \mathrm{~mol} \cdot \mathrm{L}^{-1}$

To verify the SPE/O-MWCNT modification reproducibility, the electroactive area (A) and $\mathrm{k}^{0}$ were calculated from the obtained voltammograms at different scan rates using the redox couple $\mathrm{K}_{3}\left[\mathrm{Fe}(\mathrm{CN})_{6}\right] / \mathrm{K}_{4}\left[\mathrm{Fe}(\mathrm{CN})_{6}\right]$ as a reference system. Measurements were carried out for 20 different modified electrodes, in which the RSDs of the A and $\mathrm{k}^{0}$ obtained were $3.95 \%$ and $15.3 \%$, respectively, showing an acceptable reproducibility inter-electrode. Furthermore, both A and $\mathrm{k}^{0}$ values resulted significantly increased compared to the bare electrode. Indeed, the average $(n=20)$ area obtained was $10.14 \mathrm{~mm}^{2} \pm 0.40$, while $\mathrm{k}^{0}$ was $0.021 \mathrm{~cm}^{2} \cdot \mathrm{s}^{-1} \pm 0.003$. All results shown below are reported in terms of the mean electroactive area obtained.

\subsection{Verification of the Concept}

Previously [19], we reported the possibility of quantifying glucose based on the use of a commercial glucose quantification kit [29] that measures the production of NADH after a series of enzymatic reactions described below in Equations (2) and (3).

$$
\begin{gathered}
\text { Glucose }+A T P \stackrel{\text { Hexokinase }}{\rightarrow} \text { Glucose-6-phosphate }+ \text { ADP } \\
\text { Glucose-6-phosphate }+N A D^{+} \stackrel{\text { G6P-DH }}{\rightarrow} \text { D-Glucono-d-lactone-6-phosphate + NADH }
\end{gathered}
$$


In the first step, glucose is converted to glucose-6-phosphate (G6P) by the enzymatic action of hexokinase, present in the commercial kit. In the second step, G6P is oxidized to D-gluconod-lactone-6-phosphate through an enzymatic reaction where glucose-6-phosphate dehydrogenase (G6P-DH) participates and NAD+ acts as a cofactor of the reaction and is reduced to form NADH.

The commercial kit relates the absorption of NADH at $340 \mathrm{~nm}$ with the concentration of glucose, accounting for the stoichiometrically relation between both molecules. The modification proposed here implies the electrochemical detection and quantification of the NADH produced in the second stage (Equation (3)).

Afterwards, with the aim to verify the possible culture media matrix interferers, cyclic voltammetric measurements were performed in NADH free fermentative broth and with the addition of different concentrations of NADH. The obtained voltammograms are presented in Figure 3A. Culture broth (red curve, formed by glucose $25 \%$ and peptone $1 \%$ ) showed an oxidation peak around $+0.6 \mathrm{~V}$. The signal obtained was attributable to the peptone. Indeed, it is reported that glucose at this potential and with this kind of electrode is not able to give an electrochemical response [33]. On the other hand, the voltammogram corresponding to the culture medium with an addition of NADH (blue curve) showed the presence of two signals. The first was at $0.3 \mathrm{~V}$ and attributable to the oxidation of $\mathrm{NADH}$, as confirmed with the voltammogram corresponding to the NADH standard in PBS solution (black dashed curve). Instead, the second signal corresponding to peptone appeared in around $0.6 \mathrm{~V}$, separated approximately by $0.3 \mathrm{~V}$ from NADH peak, thus it can be concluded that there was no interference between the electrochemical responses of electroactive species present in the culture broth. Because, during fermentation, one of the main components of the medium is yeast, cyclic voltammetry of Saccharomyces cerevisiae was also performed at the initial concentration at which the culture medium was prepared prior to fermentation $\left(10 \mathrm{~g} \cdot \mathrm{L}^{-1}\right)$. It was observed that the capacitive current for the yeast was significantly higher than that of the other components evaluated, probably due to its high concentration in the medium. In addition, an oxidation peak was observed at approximately $0.8 \mathrm{~V}$, as reported previously [34,35]. This signal was not identified but it did not interfere with the signal presented by NADH. It is clear that, to evaluate the presence of interferers during fermentation, a much more exhaustive characterization is necessary taking into account the complexity of the matrix; however, in these voltammograms, it was found that none of the components of the fermentation interfered with the signal of NADH, at least while this biochemical process was not taking place.
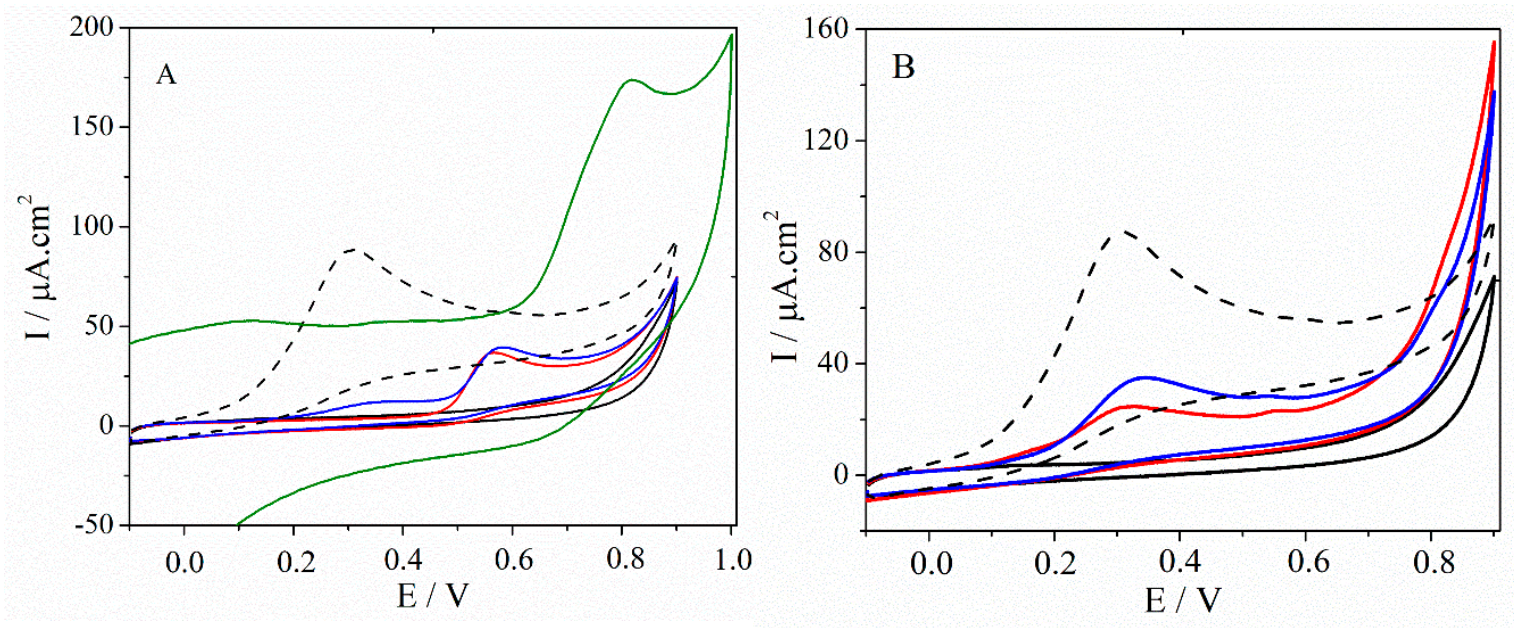

Figure 3. Cyclic voltammograms for culture broth components: (A) PBS (black), culture broth (red), culture broth + NADH $0.1 \mathrm{mmol} \cdot \mathrm{L}^{-1}$ (blue), yeast $10 \mathrm{~g} \cdot \mathrm{L}^{-1}$ (green), and NADH $1.0 \mathrm{mmol} \cdot \mathrm{L}^{-1}$ (dashed line); and (B) glucose kit components: PBS (black), commercial kit (red), kit + NADH $0.1 \mathrm{mmol} \cdot \mathrm{L}^{-1}$ (blue), and NADH $1.0 \mathrm{mmol} \cdot \mathrm{L}^{-1}$ (dashed line). Conditions: $\mathrm{pH}=7$, scan rate $0.1 \mathrm{~V} \cdot \mathrm{s}^{-1}$. 
It has been widely reported that NADH's oxidation peak potential, using unmodified graphite SPEs, shows oxidation values close to $0.6 \mathrm{~V}[16,19,36]$. Thus, O-MWNCT, used for SPE modifications, significantly decreased the NADH overpotential required to the oxidation of NADH. This behavior, particularly in this case, allowed selectively monitoring the NADH in the presence of other electroactive substances present in the matrix such as peptone.

To verify if the commercial glucose kit modified the NADH's oxidation potential or interfered with its measurement, cyclic voltammograms of the kit, the kit with the addition of NADH, and of an NADH standard solution were also carried out. Figure 3 shows the obtained voltammograms. It was found that the kit (red line) showed an oxidation signal at $0.3 \mathrm{~V}$, which could be attributed to $\mathrm{NADH}$ produced from the balance with $\mathrm{NAD}^{+}$that is present in the mixture. This was confirmed by the NADH fortification (blue line), in which the signal increased. In addition, in this case, when this signal was compared with the NADH standard in PBS (dashed line), it could be confirmed that the oxidation potential is the same.

\subsection{Electrochemical Glucose Quantification Using Chronoamperometry}

Considering the $\mathrm{CV}$ results (Figure $3 \mathrm{~A}, \mathrm{~B}$ ), a potential of $0.3 \mathrm{~V}$ was selected for the chronoamperometric quantification of glucose. Firstly, the peptone and glucose un-reactivity was evaluated, and no electrochemical response was obtained at $0.3 \mathrm{~V}$ (data not shown). Figure $4 \mathrm{~A}$ shows that stationary current was obtained from $100 \mathrm{~s}$ of chronoamperometric polarization. It is clear that the current increased as a function of glucose concentration. This agrees with the expected behavior for the current at a planar electrode and governed by the Cottrell equation [37].
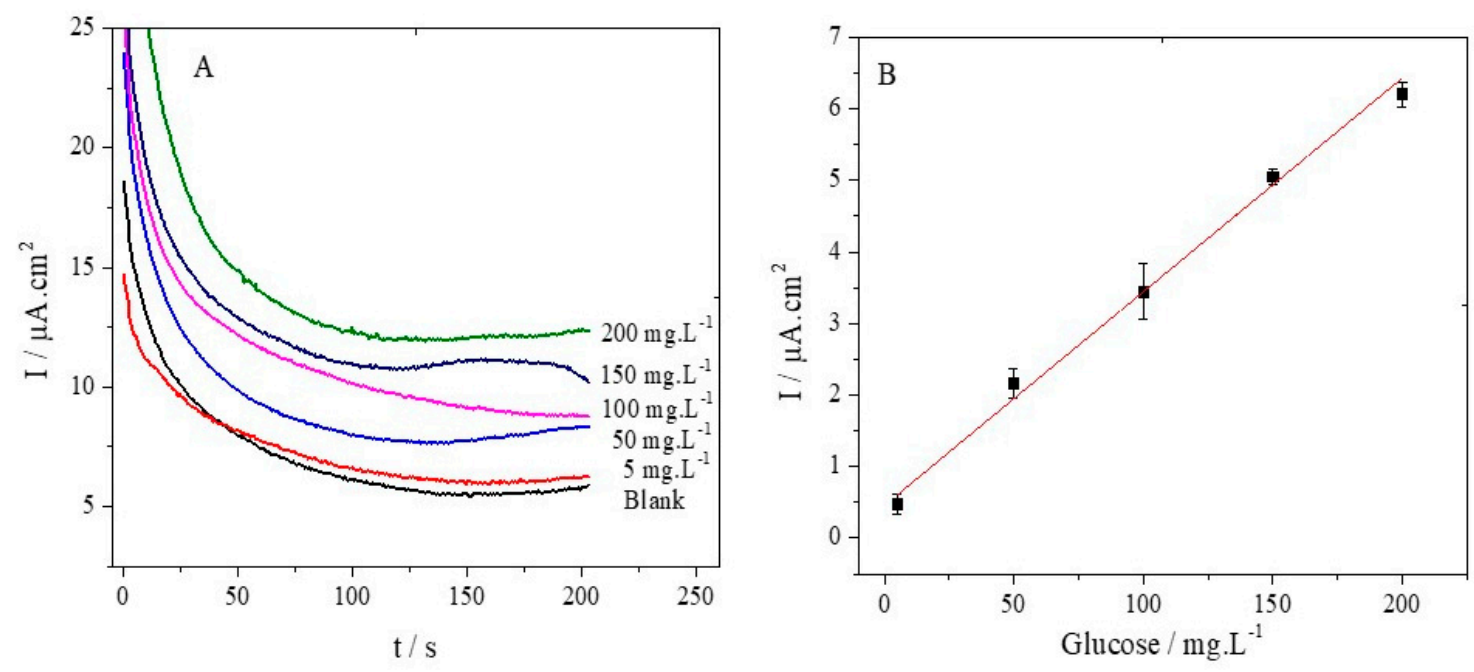

Figure 4. Chronoamperometric analysis for glucose quantification: (A) Chronoamperometry with different concentrations of glucose. Applied potential: $+0.3 \mathrm{~V}$ vs. $\mathrm{Ag} / \mathrm{AgCl}$. (B) Calibration curve taken with the last $100 \mathrm{~s}$ of each chronoamperometry. Equation: $\mathrm{I}=3.11 \times 10^{-9}$ Glucose $+4.75 \times 10^{-8}$; $\mathrm{R}^{2}=0.9931 ; p<0.05$.

The calibration curve (Figure 4B) was constructed from the average of the measured currents between 100 and $200 \mathrm{~s}$. Each point obtained for the different concentrations was subtracted from the average current obtained for the background. It can be seen that the curve showed good linearity $\left(\mathrm{R}^{2}=0.9931\right)$, and a linear range between $5 \mathrm{mg} \mathrm{L} \mathrm{L}^{-1}$ and $200 \mathrm{mg} \cdot \mathrm{L}^{-1}$. Limit of detection (LOD) and limit of quantification (LOQ) were calculated using the equations: $\mathrm{LOD}=\left(3 \mathrm{SD}_{\mathrm{B}} / \mathrm{m}_{\mathrm{CC}}\right)$ and $\mathrm{LOQ}=\left(10 \mathrm{SD}_{\mathrm{B}} / \mathrm{m}_{\mathrm{cc}}\right)$, where $\mathrm{SD}_{\mathrm{B}}$ is the standard deviation of the blank and $\mathrm{m}_{\mathrm{Cc}}$ is the slope of the linear calibration curve obtained for both equations [38]. The obtained LOD and LOQ were $16.2 \mathrm{mg} \cdot \mathrm{L}^{-1}$ and $54.1 \mathrm{mg} \cdot \mathrm{L}^{-1}$, respectively. 
Comparing the obtained analytical performance with the spectrophotometric method employed to read the glucose kit response, the sensitivity increased and the linear range covered two orders of magnitude as well as the glucose kit (50-5000 $\left.\mathrm{mg} \cdot \mathrm{L}^{-1}\right)$ [32]. Thus, the obtained LOD allows detecting, through the electrochemical process proposed, the presence of glucose in a fermentation process in a very sensitive way without optical interferers (naturally present in the fermentation broth).

\subsection{Ethanolic Fermentation Kinetics Monitoring and Glucose Evaluation Using the Proposed Strategy}

To prove the exploitability of glucose assessment using the proposed SPE/O-MWCNT-based strategy, a lab-scale fermentation was carried out. Conventional fermentation parameters as well as the decrease of glucose, using the proposed sensor, were monitored at different fermentation times. Table 1 shows the results obtained. Table 1 shows a constant decreasing, during the fermentation, of the parameters $\mathrm{pH}, \mathrm{TSS}$, and vitality, while the percentage of ethanol increased. The $\mathrm{pH}$ decrease was related to the consumption of nitrogen since for each mole of assimilable nitrogen that was consumed (in the form of ammonium or as an amino acid) a proton was released into the medium [2,39]. At the same time, secondary metabolites, including organic acids, increased and accumulated $[2,6]$.

Table 1. Time variation of the fermentation parameters.

\begin{tabular}{cccccc}
\hline $\begin{array}{c}\text { Fermentation } \\
\text { Time (h) }\end{array}$ & $\mathbf{p H}$ & $\begin{array}{c}\text { TSS } \\
\mathbf{( g \cdot 1 0 0 ~} \mathbf{g}^{-\mathbf{1}} \mathbf{)}\end{array}$ & $\begin{array}{c}\text { Ethanol } \\
\left(\mathbf{m L} \cdot \mathbf{1 0 0} \mathbf{~ m L}^{-\mathbf{1}} \mathbf{)}\right.\end{array}$ & $\begin{array}{c}\text { Viability } \\
\mathbf{( \% )}\end{array}$ & $\begin{array}{c}\text { Glucose } \\
\mathbf{( g \cdot 1 0 0} \mathbf{~ m L}\end{array}$ \\
\hline 0 & $6.78 \pm 0.03$ & $25.3 \pm 0.1$ & 0 & $81 \pm 3$ & $12.20 \pm 0.03$ \\
3 & $5.63 \pm 0.05$ & $24.8 \pm 0.1$ & $1.32 \pm 0.01$ & $68 \pm 4$ & $11.99 \pm 0.13$ \\
5 & $5.49 \pm 0.07$ & $24.3 \pm 0.2$ & $2.08 \pm 0.02$ & $65 \pm 1$ & $11.90 \pm 0.15$ \\
7 & $5.37 \pm 0.03$ & $24.0 \pm 0.3$ & $2.81 \pm 0.01$ & $63 \pm 4$ & $11.20 \pm 0.21$ \\
24 & $5.05 \pm 0.11$ & $18.3 \pm 0.1$ & $5.54 \pm 0.04$ & $59 \pm 1$ & $9.25 \pm 0.23$ \\
26 & $5.07 \pm 0.09$ & $17.8 \pm 0.2$ & $5.70 \pm 0.08$ & $46 \pm 7$ & $7.87 \pm 0.12$ \\
30 & $4.95 \pm 0.12$ & $14.5 \pm 0.4$ & $6.25 \pm 0.13$ & $45 \pm 9$ & $7.02 \pm 0.13$ \\
\hline
\end{tabular}

At the same time, the TSS value, related to dissolved sugars, decreased because yeasts metabolized these sugars to produce ethanol [2,6,7], which, as shown in Table 1, increased as a function of time. Furthermore, as expected, the yeasts cell viability decreased during the fermentation time because of metabolism inhibition related both to the increasing ethanol concentration and adverse $\mathrm{pH}$ [2].

\subsection{Correlation of Results for the Monitoring of Fermentation Kinetics}

Figure 5 presents the data shown in Table 1 and the results from the glucose quantification at different stages of the fermentation.

Considering the information presented in Table 1 and Figure 5, it is evident that the TSS estimation followed the same decreasing trend as the glucose value obtained by the proposed method. The magnitude of each electrochemically measured point corresponded to approximately half that obtained by the other technique. Indeed, TSS measures, in a non-selective way, the total "sucrose" content; in fact, the TSS technique quantifies the total soluble solids. On the other hand, the electrochemical quantification is selective for glucose, which stoichiometrically was approximately half of sucrose.

A linear correlation between the percent of glucose obtained and TSS with the proposed method was constructed. The general equation was percent glucose $=0.489 \mathrm{TSS}-0.1807$ with a linear correlation coefficient of 0.9632 and a $p$-value $<0.05$. The slope of 0.489 indicates an underestimation (as hypothesized of two-fold) of the proposed method, justifiedm as already mentioned, by the selectivity of the glucose method.

The measurement of TSS is related to the number of soluble solids dissolved in a liquid matrix. In this sense, for a relatively simple matrix such as a fermentation carried out under laboratory conditions, it is possible to correlate the measurement with the percentage of glucose (or sucrose) present in the sample. However, for more complex matrices, the measurement does not give a result 
that is absolutely correlated with glucose, since, in real systems, it is possible to find other types of soluble non-fermentable solids such as fibers, non-reducing carbohydrates, etc. For these reasons, the proposed selective and quantitative glucose measurement can be a more efficient control tool considering that the analyte of interest can be quantified directly. The obtained correlation indicates that the electrochemical method allows satisfactorily determining the glucose concentration with the advantage that it is not susceptible to matrix problems (chemical and optical) under the studied conditions. Furthermore, in several foodstuff and production processed, it is useful to selectively estimate the amount of glucose to drive a production process or to understand the maturity of a product. For these reasons, the proposed strategy could become a valid tool able to be used in microbiology, food technology, and industrial application.

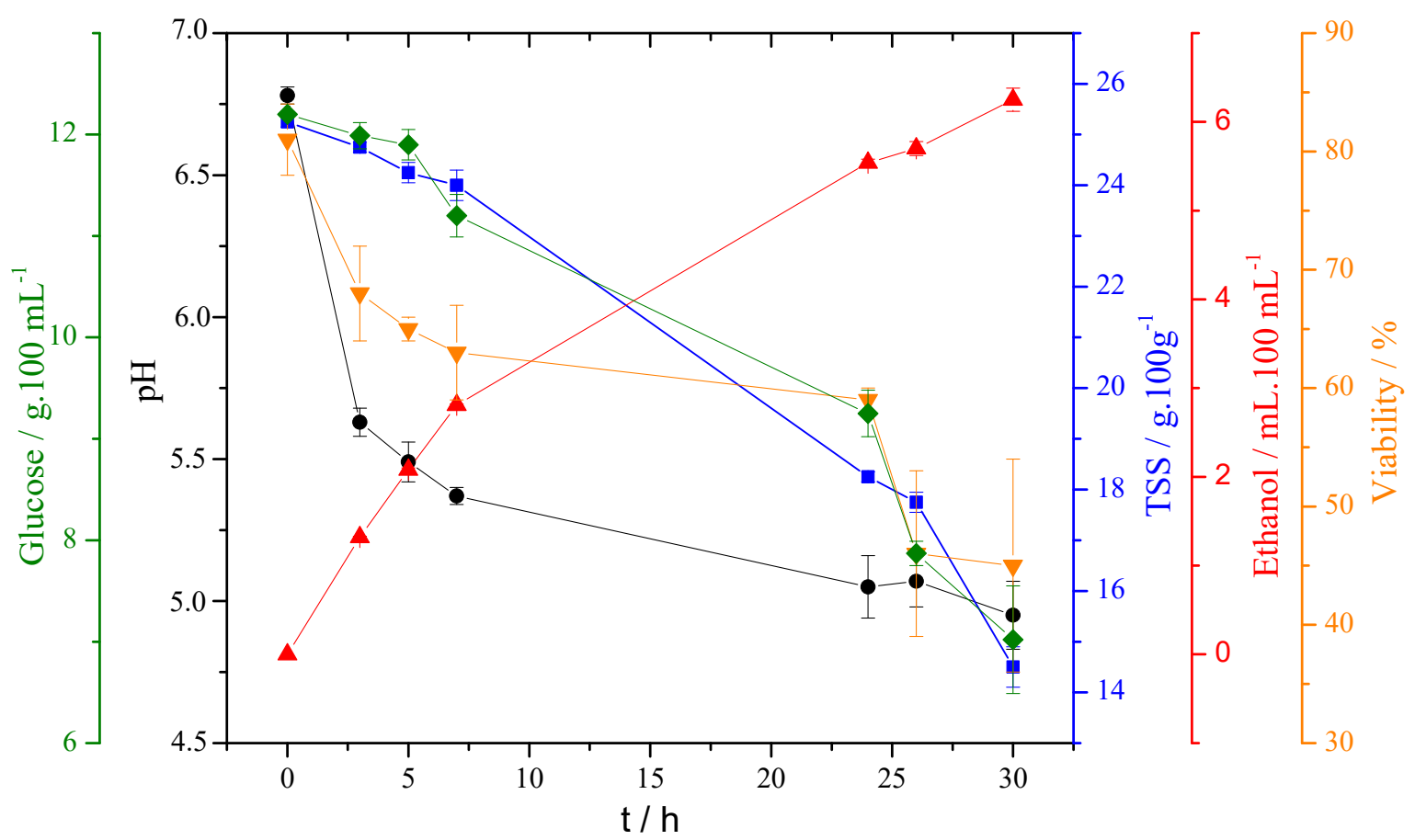

Figure 5. Time variation of the fermentation parameters: $\mathrm{pH}(\bullet)$, total soluble solids $(\square)$, percent ethanol $(\boldsymbol{\Delta})$, cell viability $(\nabla)$, and glucose $(\diamond)$.

Although in the designed sensor an enzyme is used for the quantification of glucose, it is not necessary to immobilize it, as is usually proposed in the literature for the quantification of this type of molecules $[40,41]$. On the other hand, other sensors propose the detection of glucose by "no enzyme" strategies [42,43]. While these sensors are efficient, they lose selectivity when compared to their enzyme counterparts. From this point of view, the sensor proposed in this work can be considered a hybrid between both types of detection since it is based on the indirect measurement of glucose as a result of an enzymatic reaction in homogeneous phase. In this sense, in addition to glucose quantification, the same design could be used to monitor other types of molecules, changing the type of enzyme in solution, as long as NADH is maintained as a redox mediator, which gives this electrode, greater versatility.

\section{Conclusions}

The possibility of electrochemically monitoring an ethanolic fermentation at laboratory scale was suggested. The construction of the electrode was relatively simple and reproducible. It did not require the use of intermediaries or an enzymatic modification procedure of the electrodes, which can be problematic. 
Because the glucose sensor is based on the measurement of the enzymatically generated NADH, the electrochemical response of this molecule was probed against the components of the commercial enzymatic kit and the components of the culture media used for fermentation, which can act as interferers present in the matrix. It was proved that it is possible to measure NADH without matrix interferences. Additionally, NADH measurements were tested against glucose concentration. In this experiment, the stoichiometric relationship between these two molecules was confirmed.

To evaluate the application of this system in a real domain, a lab-scale fermentation was used to determine if the built sensor was suitable for measurement in complex matrices. For indirect glucose quantification, LOD and LOQ were $16.2 \mathrm{mg} \cdot \mathrm{L}^{-1}$ and $54.1 \mathrm{mg} \cdot \mathrm{L}^{-1}$, respectively. Conventional parameters such as total soluble solids, percent ethanol, cell viability, and $\mathrm{pH}$ were measured. Electrochemical quantification of glucose, using the proposed methodology, showed a good correlation with TSS, obtaining a correlation of 0.9632 with a $p$-value $<0.05$, which, considering the complexity of the matrix, is an acceptable value.

Finally, the proposed strategy could become a valid tool able to be used in microbiology, food technology, and industrial application considering the simplicity of the method and the ability to work in real systems. In addition, the proposed strategy allows measuring samples that could present color interferences, in which the commercial spectrophotometric kit cannot be usable.

Author Contributions: Conceptualization, L.B.-N. and M.V.V.; methodology, L.B.-N. and I.A.-R.; software, L.B.-N. and J.H.-A.; validation, I.A.-R.; formal analysis, L.B.-N., J.H.-A., and F.D.P.; investigation, I.A.-R.; writing-original draft preparation, L.B.-N., J.H.-A.; and writing—review and editing, J.H.-A., M.V.V., and F.D.P.

Funding: This research was funded by the "Comité para el Desarrollo de la Investigación (CODI)", University of Antioquia, grant number 2015-7523

Acknowledgments: L.B.-N.: J.H.-A., and I.A.-R. thank Colciencias for the doctoral scholarships, grant numbers 2014-617, 2015-727, and 2017-785, respectively. M.V.V. thanks the Faculty of Exact and Natural Sciences of the University of Antioquia for the exclusive dedication granted for the project 2015-7523.

Conflicts of Interest: The authors declare no conflict of interest. The funders had no role in the design of the study; in the collection, analyses, interpretation of data; in the writing of the manuscript, or in the decision to publish the results.

\section{References}

1. Kumar, R.; Sharma, J.; Singh, R. Production of tannase from Aspergillus ruber under solid-state fermentation using jamun (Syzygium cumini) leaves. Microbiol. Res. 2007, 162, 384-390. [CrossRef] [PubMed]

2. Moreno-Arribas, M.V.; Polo, M.C. Wine Chemistry and Biochemistry, 1st ed.; Springer: New York, NY, USA, 2009; ISBN 9780387741161.

3. Giménez-Gómez, P.; Gutierrez-Capitan, M.; Capdevila, F.; Puig-Pujol, A.; Fernández-Sánchez, C.; Jiménez-Jorquera, C. Monitoring of malolactic fermentation in wine using an electrochemical bienzymatic biosensor for L-lactate with long term stability. Anal. Chim. Acta 2016, 905, 126-136. [CrossRef] [PubMed]

4. Piermarini, S.; Volpe, G.; Esti, M.; Simonetti, M.; Palleschi, G. Real time monitoring of alcoholic fermentation with low-cost amperometric biosensors. Food Chem. 2011, 127, 749-754. [CrossRef] [PubMed]

5. Florescu, M.; Brett, C.M.A. Development and evaluation of electrochemical glucose enzyme biosensors based on carbon film electrodes. Talanta 2005, 65, 306-312. [CrossRef]

6. Esti, M.; Volpe, G.; Compagnone, D.; Mariotti, G.; Moscone, D.; Palleschi, G. Monitoring Alcoholic Fermentation of Red Wine by Electrochemical Biosensors. Am. J. Enol. Vitic. 2003, 54, 39-45.

7. Nelson, D.; Cox, M. Lehninger. In Principles of Biochemistry, 5th ed.; W.H. Freeman: New York, NY, USA, 2004; ISBN 9781429234146.

8. Radoi, A.; Compagnone, D. Recent advances in NADH electrochemical sensing design. Bioelectrochemistry 2009, 76, 126-134. [CrossRef] [PubMed]

9. Bianco, P. Bioelectrochemistry. In Encyclopedia of Electrochemistry, 1st ed.; Bard, A.J., Stratmann, M., Wilson, G.S., Eds.; Wiley: New York, NY, USA, 2002; Chapter 9; pp. 67-145. 
10. Omar, F.S.; Duraisamy, N.; Ramesh, K.; Ramesh, S. Conducting polymer and its composite materials based electrochemical sensor for Nicotinamide Adenine Dinucleotide (NADH). Biosens. Bioelectron. 2019, 79, 763-775. [CrossRef] [PubMed]

11. Luo, X.; Li, R.; Yan, L. Roles of Pyruvate, NADH, and Mitochondrial Complex I in Redox Balance and Imbalance in $\beta$ Cell Function and Dysfunction. J. Diabetes Res. 2015, 2015, 512618. [CrossRef] [PubMed]

12. Wilhelm, J.; Hirrlinger, F. Multifunctional roles of NAD ${ }^{+}$and NADH in astrocytes. Neurochem. Res. 2012, 37, 2317-2325. [CrossRef] [PubMed]

13. Elving, P.J.; Breshahan, W.T.; Moiroux, J.; Samec, Z. NAD ${ }^{+} / \mathrm{NADH}$ as a model redox system: Mechanism, mediation, modification by the environment. Bioelectrochem. Bioenergy 1982, 9, 365-378. [CrossRef]

14. Zhang, M.; Smith, A.; Gorski, W. Carbon nanotube-chitosan system for electrochemical sensing based on dehydrogenase enzymes. Anal. Chem. 2004, 76, 5045-5050. [CrossRef] [PubMed]

15. Blandón-Naranjo, L.; Hoyos-Arbeláez, J.; Vázquez, M.V.; Della Pelle, F.; Compagnone, D. NADH Oxidation onto different carbon-based sensors: Effect of structure and surface-oxygenated groups. J. Sens. 2018, 2018, 6525919. [CrossRef]

16. Zhang, L.; Li, Y.; Zhang, L.; Li, D.W.; Karpuzov, D.; Long, Y.T. Electrocatalytic oxidation of NADH on graphene oxide and reduced graphene oxide modified screen-printed electrode. Int. J. Electrochem. Sci. 2011, 6, 819-829.

17. Radoi, A.; Compagnone, D.; Valcarcel, M.A.; Placidi, P.; Materazzi, S.; Moscone, D.; Palleschi, G. Detection of NADH via electrocatalytic oxidation at single-walled carbon nanotubes modified with Variamine blue. Electrochim. Acta 2008, 53, 2161-2169. [CrossRef]

18. Arduini, F.; Amine, A.; Majorani, C.; Di Giorgio, F.; De Felicis, D.; Cataldo, F.; Moscone, D.; Palleschi, G. High performance electrochemical sensor based on modified screen-printed electrodes with cost-effective dispersion of nanostructured carbon black. Electrochem. Commun. 2010, 12, 346-350. [CrossRef]

19. Blandón-Naranjo, L.; DellaPelle, F.; Vázquez, M.V.; Gallego, J.; Santamaría, A.; Alzate-Tobón, M.; Compagnone, D. Electrochemical Behaviour of Microwave-Assisted Oxidized MWCNTs Based Disposable Electrodes: Proposal of a NADH Electrochemical Sensor. Electroanalysis 2018, 30, 1-9. [CrossRef]

20. Pérez-López, B.; Merkoçi, A. Nanomaterials based biosensors for food analysis applications. Trends Food Sci. Technol. 2011, 22, 625-639. [CrossRef]

21. Della Pelle, F.; Compagnone, D. Nanomaterial-Based Sensing and Biosensing of Phenolic Compounds and Related Antioxidant Capacity in Food. Sensors 2018, 18, 462. [CrossRef] [PubMed]

22. Ligler, F.S.; White, H.S. Nanomaterials in Analytical Chemistry. Anal. Chem. 2013, 85, 11161-11162. [CrossRef] [PubMed]

23. Della Pelle, F.; Angelini, C.; Sergi, M.; Del Carlo, M.; Pepe, A.; Compagnone, D. Nano carbon black-based screen printed sensor for carbofuran, isoprocarb, carbaryl and fenobucarb detection: Application to grain samples. Talanta 2018, 186, 389-396. [CrossRef] [PubMed]

24. Rojas, D.; Della Pelle, F.; Del Carlo, M. Electrodeposited Prussian Blue on carbon black modified disposable electrodes for direct enzyme-free $\mathrm{H}_{2} \mathrm{O}_{2}$ sensing in a Parkinson's disease in vitro model. Sens. Actuators $B$ Chem. 2018, 275, 402-408. [CrossRef]

25. Capoferri, D.; Della Pelle, F.; Del Carlo, M.; Compagnone, D. Affinity Sensing Strategies for the Detection of Pesticides in Food. Foods 2018, 7, 148. [CrossRef] [PubMed]

26. Cinti, E.; Basso, M.; Moscone, D.; Arduini, F. A paper-based nanomodified electrochemical biosensor for ethanol detection in beers. Anal. Chim. Acta 2017, 960, 123-130. [CrossRef] [PubMed]

27. Della Pelle, F.; Di Battista, R.; Vázquez, L.; Palomares, F.J.; Del Carlo, M.; Sergi, M.; Compagnone, D.; Escarpa, A. Press-transferred carbon black nanoparticles for class-selective antioxidant electrochemical detection. Appl. Mater. Today 2017, 9, 29-36. [CrossRef]

28. Della Pelle, F.; Vázquez, L.; Del Carlo, M.; Sergi, M.; Compagnone, D.; Escarpa, A. Press-Printed Conductive Carbon Black Nanoparticle Films for Molecular Detection at the Microscale. Chem. A Eur. J. 2016, 22, 12761-12766. [CrossRef] [PubMed]

29. Steroglass. Technical Note: Kit Glucosio-Fruttosio; San Martino In Campo: Perugia, Italy, 2011.

30. Martín-Yerga, D.; Rama, E.C.; García, A.C. Electrochemical Study and Determination of Electroactive Species with Screen-Printed Electrodes. J. Chem. E 2016, 93, 1270-1276. [CrossRef]

31. Nicholson, R.S. Theory and Application of Cyclic Voltammetry f m Measurement of Electrode Reaction Kinetics. Anal. Chem. 1965, 37, 1351-1355. [CrossRef] 
32. Sigma-Aldrich. Technical Note: Glucose (HK) Assay Kit; Sigma-Aldrich: St. Louis, MO, USA, $2003 ;$ p. 715824.

33. Kruid, J.; Fogel, R.; Limson, J. Voltammetric investigation of complex growth media at a bare glassy carbon electrode: A case study of oxytetracycline. Electrochim. Acta 2014, 128, 41-47. [CrossRef]

34. Tsukatani, T.; Ide, S.; Oba, T.; Ukeda, H.; Matsumoto, K. Electrochemical Measurement of Yeast Cell Density and Vitality Using 2,3,5-Trimethyl-1,4-benzoquinone and Effect of Ethanol on the Metabolism of Quinone by Yeast Cells. Food Sci. Technol. Res. 2003, 9, 271-275. [CrossRef]

35. Ci, Y.-X.; Feng, J.; Jiang, Z.-W.; Luo, D.-Z. The voltammetric behavior of Saccharomyces cerevisiae. Bioelectrochem. Bioenergy 1999, 43, 293-296. [CrossRef]

36. Radoi, A.; Compagnone, D.; Batič, M.; Klinčar, J.; Gorton, L.; Palleschi, G. NADH screen-printed electrodes modified with zirconium phosphate, Meldola blue, and Reinecke salt. Application to the detection of glycerol by FIA. Anal. Bioanal. Chem. 2007, 387, 1049-1058. [CrossRef] [PubMed]

37. Wang, J. Analytical Electrochemistry, 3rd ed.; John Wiley \& Sons, Inc.: Hoboken, NJ, USA, 2006; ISBN 9780471790303.

38. Harris, D.C. Quantitative Chemical Analysis, 7th ed.; W.H. Freeman and Company: New York, NY, USA, 2007; ISBN 0716770415.

39. Lin, Y.-H.; Chien, W.S.; Duan, K.J. Correlations between reduction-oxidation potential profiles and growth patterns of Saccharomyces cerevisiae during very-high-gravity fermentation. Process Biochem. 2010, 45, 765-770. [CrossRef]

40. Wang, J. Electrochemical glucose biosensors. Chem. Rev. 2007, 108, 814-825. [CrossRef] [PubMed]

41. Lee, H.; Yongseok, J.H.; Baik, S.; Hyeon, T.; Dae-Hyeong, K. Enzyme-Based Glucose Sensor: From Invasive to Wearable Device. Adv. Healthc. Mater. 2018, 7, e1701150. [CrossRef] [PubMed]

42. Dae-Woong, H.; Saram, L.; Minjee, S.; Taek, D.C. Recent advances in electrochemical non-enzymatic glucose sensors-A review. Anal. Chem. Acta 2018, 1033, 1-34. [CrossRef]

43. Toghill, K.E.; Compton, R.G. Electrochemical Non-enzymatic Glucose Sensors: A Perspective and an Evaluation. Int. J. Electrochem. Sci. 2010, 5, 1246-1301.

(C) 2019 by the authors. Licensee MDPI, Basel, Switzerland. This article is an open access article distributed under the terms and conditions of the Creative Commons Attribution (CC BY) license (http:/ / creativecommons.org/licenses/by/4.0/). 